\title{
Memetic Engineering for Permanent Education in Line with Sustainable Growth
}

\author{
C.I. Brumar, R.D. Fabian, M.-J. Manolescu, V. Chiş
}

Cristina I. Brumar, Ralf D. Fabian

Lucian Blaga University of Sibiu

Romania, 550024 Sibiu, 10 Bd.Victoriei

E-mail: crista.brumar@gmail.com, ralf.fabian@gmail.com

Mişu-Jan Manolescu

Agora University, Romania,

Piata Tineretului, 8, 410526 Oradea, Romania,

E-mail: mmj@univagora.ro

Violeta Chiş

Aurel Vlaicu University of Arad

Faculty of Exact Sciences

Department of Mathematics-Informatics

Romania, 310330 Arad, 2 Elena Dragoi

E-mail: viochis@yahoo.com

\begin{abstract}
:
Given the recent point of view of the European Commission regarding the implementation of a new strategy for sustainable growth and jobs, this paper emphasises the opportunity and urgency of supporting the EU 2020 strategy, providing an appropriate educational tool for the knowledge society. The main objectives are: a. adapting memetic engineering expressed in terms of General System Theory to the teaching component of permanent education based on bounded rationality and "Just in Time" as key tools for fighting cognitive chaoplexity in the post-industrial era; b. facilitating the use of memetic engineering based on its double-faceted nature: as both positive and negative feedback; c. extending the applicability of memetic engineering to ecology as source of memes; d. exemplifying the above in primitive metamodels applying memetic engineering in ecology and highlighting the relevant design-space dimensions. Among the conclusions: a. to be sustainable in the long run permanent education must be modelled in line with learner bounded rationality, since bounded rationality is a psychological lasting feature; b. sustainable development depends on affordable permanent education; c. as a result, e-teaching should be systematically revisited through intense transdisciplinary research.

Keywords: sustainable growth, permanent education, bounded rationality, chaoplexity, memetic engineering.
\end{abstract}

\section{Introduction}

Given the recent point of views of the European Commission (March 2, 2012, Brussels [13]) regarding the implementation of a new strategy that "pursues both continued fiscal consolidation and determined action to boost growth and jobs; sustainable growth and jobs cannot be built on deficits and excessive debt levels" [13], this paper follows the requirements and urgency of implementing the strategy [13], namely strengthening and development of actions to achieve continuous growth of services and economy. At the European level, after renewing the Lisbon strategy through the EU 2020 strategy, lifelong learning is regarded as key pillar of sustainable growth. Permanent education based on skills acquired through dynamic knowledge, recognizes the failure of static knowledge-based lifelong learning through Learning Objects Repositories [16]. 
Since education is seen as a complex service in a post-industrial era, this paper aims to extend to ecology the general educational tool for knowledge society as proposed in [20], [19], [16], [6].

Dominant features of the post-industrial era are summarized and explained in [10] as: "a) Growing speed of change (due to the intense positive feedback entailed by Moore's law outcomes: Internet, broad-band technology, semantic Web, Google, etc.). b) Growing complexity (architectural, cognitive, structural). c) Globalization (expressed in IT context mainly through the modern enterprise paradigms). [...] Thus, modern IT environments, except for simple applications, move towards open and heterogeneous (resources are unalike and their availability is not warranted), dynamic (the pace of exogenous and endogenous changes is high) and uncertain (both information and its processing rules are revisable, fuzzy, and uncertain). Most situations to be controlled are complex and uncertain, and involve parallel processes." [10].

Thus, after updating related work in Section 2, the paper tracks the first objective in Section 3 investigating the main concepts related to memetic stability. On this groundwork, as bounded rationality and "Just-in-Time" were tools for e-teaching [16], Section 4 is build as paper core: it launches the concept of memetic engineering regarded as tool for research in ecology - since it matches with e-teaching environmental science. Section 5 highlights the design-space dimensions of a (primitive) metamodel for the "integral ecology" [12]. Conclusions and future work (Section 6) close the paper.

\section{Rationale and Related Work}

Considering the far range target of sustainable growth, the milestones are set up by the Europe 2020 strategy: "and if Europe is to emerge stronger from the crisis, we need more than ever to stimulate smart and green economic growth, underpinned by knowledge and innovation as its key drivers. [...] we need to focus on policies that give a chance to everyone to develop one's skills and live in dignity. [...] Our common aim is to provide a sustainable response to the many challenges facing us to transform the European Union into a knowledge-based, resource efficient and low-carbon economy" [2]. That means that the students have to learn how to be skilled (chaoplexity teaching for permanent education based on bounded rationality), how to reduce the ecological damage made by economic growth (ecological systems based on memetic engineering), and we need to prepare them for what comes next (students have to live based on very different principles).

As regards the concept of meme, a short definition might be: a meme is a unit of information residing in the brain and is the mutating replicator in human cultural evolution (Richard Dawkins, [8]). Slogans, riddles, songs, signs, inventions and fashions are typical memes. An idea or information pattern is not a meme until it causes someone to spread, to transmit it to another. "Why another new "....tics"? Memetics is a key Zeitgeist-component and is transdisciplinary par excellence; The "Self" memotype shows a cognitive complexity similar to the structural one of the genotype; The "Self-*" memeplex invaded modern IT ("star" = awareness) [...]; The thick-time meme is vigorous and old (preceded AI itself)" [1].

"According to the theory Memetic Engineering is, simply put, the analysis of an individual or individual's behaviour, the selection of specific memes and the distribution or propagation of those memes with the intent of altering the behaviour of others". [http://en.wikipedia.org/wiki/ Memetic_engineering]. Including memetics in this paper (as shown in [16]) is reasonable because most paradigms in modern artificial intelligence have a memetic character and this phenomenon is ever more important in an increasing chaoplexic world [16]. Memes are transdisciplinary par excellence and they originate from myths that represent valuable sources of metaphors - an obvious source of stability.

Hence, the research about the role of permanent education for sustainable growth as well as 
the role of memetic engineering in permanent education [19], [16], [20], [6] has been continued in line with the following objectives: a) adapting memetic engineering expressed in terms of General System Theory to the teaching component of permanent education based on Bounded Rationality and "Just-in-Time" as key tools for fighting cognitive chaoplexity in post-industrial era [16]; b) facilitating the use of memetic engineering based on his double faceted nature: as negative feedback (through memetic stability) and positive feedback (through intense spreading of memes); c) extending the applicability of memetic engineering from myths and metaphors, including (paleo)linguistics [16], to ecology as source of memes; d) exemplifying the above in primitive metamodels applying memetic engineering in ecology and highlighting the relevant design-space dimensions. Sustainable growth depends on permanent education; this involves memetic engineering and bounded rationality, and requires changes in the three referred fields: cognitive psychology, IT, and Higher Education.

For the sake of self-containment the paper summarises some results of [16], [6], [20] underlining the transdisciplinary aspects related to: psychology, semantics, vital service, skill oriented and self-organizing (lifelong) learning, corpus of knowledge, intensely dynamic and uncertain environments.

\section{Main Concepts related to Memetic Stability}

Norbert N. Seel in "Encyclopedia of the Sciences of Learning" [22] proposed an interdisciplinary overview about learning and the connections between different fields of sciences: "Over the past century, educational psychologists and researchers have posited many theories to explain how individuals learn, how they acquire, organize and deploy knowledge and skills. [...] As the learning sciences became more specialized and complex, the various fields of interest were widely spread and separated from each other; as a consequence, even presently, there is no comprehensive overview of the sciences of learning or the central theoretical concepts and vocabulary on which researchers rely. Learning theories are not limited to psychology and related fields of interest but rather we can find the topic of learning in various disciplines, such as philosophy and epistemology, education, information science, biology, and - as a result of the emergence of computer technologies - especially also in the field of computer sciences and artificial intelligence." [22].

Three memetic features should be focused on to ease applying them in permanent education [16]: a) lastingness (they are a leitmotif in cultural history); b) ubiquitousness (they permeate all cultures); c) effectiveness (they are active now in education) [16], [6]. Even without prior knowledge of psychology it is well-known that behaviours are extremely lasting. Hence, they can illustrate the role of Bounded Rationality as "educational mechanism" much more convincingly than widespread topics - albeit very famous. The three steps are similar to those above: a) choosing the pervasive habit of scoring (instead of counting) - scoring was - and still is - certainly easier than counting; b) investigating the related memeplex; c) proposing a boundedly rational way to exploit simplicity in e-teaching.

Memetic engineering for permanent education tries to integrate transdisciplinary sciences. In recent papers [19], [20] bounded rationality and "Just-in-Time" were used as tool for e-teaching; this paper aims at proving that memetic engineering for permanent education is a tool for eteaching environmental science. Ecologists use memetic stability because they want to preserve the environment.

As regards the concept of chaoplexity, it reveals its value in military operational research: "Chaoplexic warfare draws on the study of nonlinear phenomena of self-organization to propose a radical decentralization of armed forces through the adoption of the network form. [...] Information remains the central concept, and in this sense chaoplexity is an outgrowth of cybernetics; but the focus on change, evolution and positive feedback breaks with the cybernetic pioneers' 
concern for stability" [4]. To add a flavour to the syntagm "educational chaoplexity" (EDCHY): "In association with the respective technologies of the clock, engine and computer, the scientific theories of mechanism, thermodynamics, and cybernetics have all in turn been recruited to shape distinct approaches to the challenges of imposing order on the chaos of the battlefield. Today, it is on the basis of the new sciences of chaos and complexity that the latest regime of the scientific way of warfare is being erected" [4], [19]. In the abbreviation EDCHY, the focus is on the letters $\mathrm{d}$ and $\mathrm{h}$ because education has to take into account that we live in a dynamic and heterogonous environment. Concerning ecology, even if the time span is larger implied in EDCHY regarding learning, climatic changes take place during thousands of years. Hence "Just-in-Time" measures should be taken to ensure environment preservation - an obvious chaoplexic issues.

In short: permanent education relies on bounded rationality and "Just-in-Time". Bounded rationality can be used as a tool to educational chaoplexity and as common denominator for the two facets of permanent education, namely e-teaching and e-learning. "Just-in-Time", as connotation of "real time", is related with the role of response time (vital in any teacher-learner interaction) [5]. Permanent education involves "Just-in-Time" synchronization between e-teaching and e-learning and is basic for the shift from product-based to a service-based society [16], [6]. The links to memetic stability will become evident in the next section.

\section{Double Faceted Nature}

In line with common linguistic usage, positive and negative has connotations different from the scientific ones: stability (as negative feedback) has positive effect while creativity (as positive feedback) could become extremely risky - if not restricted.

\subsection{Negative Feedback through Memetic Stability}

"Negative feedback helps to maintain stability in a system in spite of external changes. It is related to homeostasis. For example, in a population of foxes (predators) and rabbits (prey), an increase in the number of foxes will cause a reduction in the number of rabbits; the smaller rabbit population will sustain fewer foxes, and the fox population will fall back." [http://en.wikipedia.org/wiki/Feedback]. On the same sight appear other correct sentences, but using the contrasting connotation: "In an electronic amplifier feeding back a negative copy of the output to the input will tend to cancel distortion, making the output a more accurate replica of the input signal" or even "Positive feedback amplifies possibilities of divergences (evolution, change of goals); it is the condition to change, evolution, growth; it gives the system the ability to access new points of equilibrium" [Wikipedia]. [...] Some assertions need badly to be improved (e.g., "Negative feedback, which tends to reduce the input signal that caused it, is also known as a self-correcting or balancing loop. [...] The terms negative and positive feedback can be used loosely or colloquially to describe or imply criticism and praise, respectively. This may lead to confusion with the more technically accurate terms positive and negative reinforcement, which refer to something that changes the likelihood of a future behaviour." [Wikipedia]).

Almost always in nature (e.g., homeostasis in living beings) and very often in technology (e.g., reducing noise and message distortion in communication systems), the target looked for is preservation (e.g., in living systems to prevent decay), or stability (e.g., in artificial systems to prevent deterioration). This basic kind of feedback is called - for obvious historical and physical reasons - negative feedback [16].

For permanent education, negative feedback is sine qua non, above all for the teaching process because it is corrective, promotes stationariness, stability, and reversibility; (e.g. ecologists are based on traditions and, some time, on people's inertia). 
In short: IT and memetic engineering provides to ecologists tools to handle environmental issues and to decide what is sustainable or not sustainable for them. Memetics helps indirectly in the sense of tradition, because ecology implies environment stability.

\subsection{Positive Feedback through Spreading of Memes}

Positive feedback means creativity; using positive feedback, the parameter values are increased, the whole process is evolutive, innovative, generating chain reactions that increase instability and involve irreversibility. Concerning ecology, positive feedback refers to the countermeasures to be taken to oppose/face environment degradation. (E.g. Since the environment is preserved by fighting/opposing nuclear energy, specialists have to be creative to find methods for supplying energy without destroying the environment).

With no doubt language and culture are close related and have been subject of sociological, anthropological and memetic research [3], [8]. Language is determined by culture (ancient civilisations did not have words for computer, internet, phone, television, radio, etc.) but culture is determined by language too, if memes are regarded as fundamental replicators for their evolution.

Richard Dawkins emphasised in "The Selfish Gene" [8] the importance of thinking about evolution in terms of information that can be transferred from one person to another via imitation [8]. On this groundwork Susan Blackmore in "The Meme Machine" asserts: "Just as the design of our bodies can be understood only in terms of natural selection, so the design of our minds can be understood only in terms of memetic selection." [3] According to her, language developed as result of memetic evolution and is the principal medium used for spreading memes, i.e. replicating themselves in as many minds as possible.

Traditionally, spreading of memes was through word-of-mouth followed by written word and printed word. Today memetic propagation via language takes advantages of globalization and of a wide media spectrum (i.e., radio, television, internet, etc.) and of increasing propagation speed due to intense positive feedback (id est., Moore's Law and the new technologies based on it) $[10]$.

Talking about internet, it is impossible to ignore the meme spreading power of search engines. Without them information would be hard to reach. Moreover, by email, newsgroups, message boards and social networks people can circulate their memes allowing adherents to unpopular/popular memes to come together ideologically. Companies already promote memes this way to advertise their products by viral marketing strategies.

Internet and IT\&C in general "is becoming a tool for social interaction bridging the strands between online and offline activities, respectively, digital and social behaviour. [...] Information and Communication Technologies (ICT) experienced in people's everyday life sets a milestone for an active participation in the Knowledge Society" [17]. At European level, it is still a basic pillar of the strategy for growth: "High-speed Internet underpins all sectors of the economy and will be the backbone of the Digital Single Market. For every $10 \%$ increase in the broadband penetration the economy grows by 1 to $1.5 \%$." [14]. Of course, this stimulates the speed of meme propagation.

Memes are spread by copying and suffer modifications in their evolution - similar to genes. Thus, the newness, the sparkle of creativity is within mutation, since it exceeds the possibilities of simple copying from crossover (when Archimedes came out of bath exclaiming "Eureka" he was not copying anyone). Thinking in terms of Genetic Algorithms, crossover is perceived as negative feedback, preserving stability by selecting and copying fittest the properties from parents to their offspring, whereas positive feedback manifests itself creatively in mutations, giving rise to new unpredictable, hence non-deterministic outcome. Corollary: memetic evolution (and also genetic algorithms) involves intrinsically non-determinism. That is why non-deterministic software is 
used in IT [16] - to be able to exploit positive feedback too.

In short, technology in first place, only eases rapid spreading and gives no clue about the effect of a meme. To decide if a meme is toxic or not, is still up to the end-user.

The contradiction between negative feedback - fundamental for stability required by ecologists - and positive feedback - fundamental for growth - can be solved only by approaching the problem through General System Theory (GST). Any sectorial, partial, local or parochial solutions for solving the problems are inappropriate, because these solutions are not only for a limited biocenosis but have to be for a global ecosystem. Consequently, holistic analyses of situations are sine qua non and the tools for handling these situations must also be holistic [16]. Examples and explanations inspired by integral ecology [12] are abridged below.

Based on a large public acceptance of renewable energy, the hype around wind energy developed significantly in the last years, promoting wind turbines and wind farms as one ecological sustainable solution for green energy [18]. A recent report praises the wind energy as "recessionbusting industry" for its impact as "Green growth" on jobs and economy [15]. Beside benefits of green energy, e.g. no air pollution, moderate capital cost, low ongoing costs, energy independence, several side-effects came to fore. Wind farms need to be placed in wide areas for great efficiency. Reports of bird and bat mortality argue that wind turbines are artificial structures that interfere and destroy ecosystems, especially in regions where there are important flight paths for migratory bird [21], [9]. Furthermore, aesthetic impact, sound emission or even increase of night time temperatures [7] are part of the price to pay when it comes to green energy. To which extend the ecological impact is significant or not is still in question but it clearly leads to an "Environmental Paradox" [11] that ecologists have to deal with.

As regards environment, preservation is a legitimate endeavour whereas wild altering proved to be harmful. Memetic stability is consistent with the requirement for stability of environment preservation whereas creativity, in unconventional technological approaches, is shaping hope for finding proper solutions.

Climate change is linked subjective and objective to "Just-in-Time". That is, ecology has as main target conservation whereas climate change is perceived memetically as slowly. In this context "Just-in-Time" could be understood as a secondary restriction since there is enough time to fight climate change and find solution. Such arguments are perhaps convenient for emerging industries, pushing limits, conventions and boundaries as far as possible in the future (e.g. Kyoto Protocol). On the other hand, relying on the meme that climatic changes are slowly and considering that the last significant climate change of human history, the glacial period, dates of approximate 20 millenniums ago, means ignoring heavy side effects, like Hurricane Katrina or El Niño phenomena, with evolutions visible even in periods shorter than a human lifespan. Hence, solutions are addressable only through bounded rationality, "Just-in-Time" and chaoplexity together.

That is why holistic approaches are needed; any reductionist view leads to solutions that could hardly satisfy ecosystem stability and sustainable growth.

\section{Metamodel}

Nowadays, the world's natural resources are under pressure. Actions as soil erosion, acid rain, the extinction of species, have all contributed to the environmental system damage. "Economic production influences the environment in many ways, through the consumption of energy and natural, often non-renewable resources, and the production of pollution, toxic wastes, etc. They further stressed (not without opposition) that present environmental problems require a new type of development process which harnessed the benefits of economic growth without the damaging consequences which growth can have on the environment. Up to now, technology has been 
developed for the sole purpose of increasing economic and social standards, with little or no regard for its potential negative impact on the environment (e.g. exhaustion of non-renewable resources, extinction of species, eutrophication, acidification, ozone-depletion, etc.)" [23].

Understanding human diversity through cultural value and thinking, enables an approach to education that explains different outcomes of choices people make. The challenge is for explaining the thinking that led to certain behaviour and not for behaviour itself. Since memes being decision-systems transcending culture, society and evolution, the struggle is with the memes in humans that are at rumour. To name some memes in ecologic field: nuclear power plant Fukushima - economic efficiently but ecological disaster; whaling - coastal communities have long tradition and industrial level emerged as technology increased, but whaling is immoral, unsustainable, and should be banned.

As regards Memetic Engineering as antidote to vicious memes, it has been shown that "folklore can be harmful when myths are not dismantled before being disseminated as memes. The need to counteract them is obvious and memetic engineering is just the newest arm in the well assorted panoply of persuasive means, from ancient rhetoric to modern aggressive advertising." [16].

With the growing economy, we use a lot of resources which will regenerate in years, and therefore, if there are not taken certain measures from an ecological point of view, we exhausted all resources. Today's youth must be trained to meet this challenge, and for that we need to "e-teach" environmental science. The field of ecology is manifold and should be treated from a transdisciplinary point of view. Hence, it is appropriate to create a primitive metamodel for ecology (its relevant design-space metadimensions are shown in Figure 1). Sean EsbjörnHargens in his article [12] wrote about the existence of four correlated dimensions to approach ecological issues. "Integral Ecology inquires into all for quadrants, or four Terrains: Behavioral Terrain (behaviors at all levels of organization), Experience Terrain (experiences at all levels of perception), Systems Terrain (systems at all levels of ecological and social intersection), and Cultural Terrain (cultures at all levels of mutual resonance and understanding)" [12].

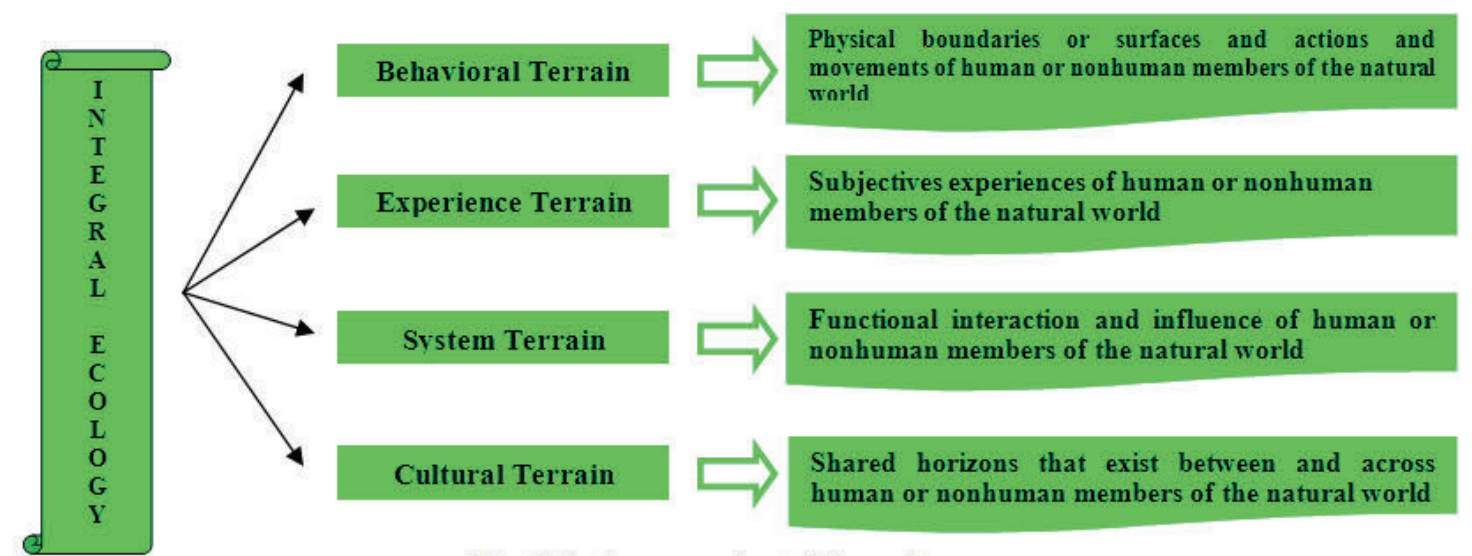

Fig. 1 Design-space (meta)dimensions.

In short: memetic engineering based on bounded rationality and "Just-in-Time" fits in all four terrains, but of course is the right and the duty of the end-user (i.e. researchers in ecology) to choose and to prioritise those terrains or maybe some blend of them.

\section{Conclusions and future work}

Starting of the outcomes of [16], the conclusions are: a) to be sustainable in the long run permanent education must be modelled in line with learner bounded rationality, since bounded rationality is a psychological lasting feature; b) for sustainable development e-teaching should 
be systematically revisited through intense transdisciplinary research; c) in line with the EU 2020 strategy, education for sustainability involves also to develop metamodels in the field of integral ecology using memetic engineering to alleviate the apparent opposition between economic growth and environment preservation; d) time has to be dealt with carefully since teaching and learning take place in different temporal frameworks. Any educational process that is changing and adapting every day has to be in accordance with the new strategy; memetic stability helps creating a new king of e-teaching. Some corollaries are: a) IT provides ecologists, in their attempt to preserve environment, a useful tool: memetic engineering is applied to put to work useful memes and to avoid vicious memes; b) to be sustainable on the long run lifelong learning needs eteaching based on innovation and "out of the box" thinking; c) IT tools avoiding nondeterministic software are inefficient because of the evolutionary unpredictable processes, both memes and genes are based on.

As regards future work, to be reliable, the research should be separated regarding research object (ecology) and method (memetic engineering). In this respect, the intention is to develop methods based on memetic engineering where memes are more appropriate applied, namely in Decision Making adapting the way decisions will be described in a future work dedicated to strategic decisions for environment preservation.

\section{Bibliography}

[1] Bărbat, B.E., NEWTON, HUSSERL, WIENER: A Temporal Golden Braid (Invited paper at Int. Conf. on Comput. Commun. and Control, ICCCC 2010, Oradea), in Abstracts of ICCCC Papers, ISSN 1844-4334, pp. 12. 2010.

[2] Barroso J. M. D., Urban areas, drivers of growth and jobs, 5th European Summit of Regions and Cities, Copenhagen, 22 march 2012.

[3] Blackmore S., The Meme Machine, Oxford University Press, 2000.

[4] Bousquet A., Chaoplexic warfare or the future of military organization, International Affairs, 84(5):915-929, Wiley Online Library, 2008.

[5] Brumar C. I., R. D. Fabian, Bărbat B.E., CSITAO Carnap-like Glossary: http://bcu.ulbsibiu.ro/digitale/doctorate/glossary_csitao.pdf.

[6] Brumar C. I., Sustainable Development in spite of Educational Chaoplexity. State of the Art, First Technical Report for the PhD Thesis titled "Nondeterministic e-Teaching in Uncertain, Dynamic Environments. Experimental Model based on Memetic Engineering", LBUS, 2011: http://bcu.ulbsibiu.ro/digitale/doctorate/Cristina_Brumar_Ref1_Presentation.pdf.

[7] Carrington D., Wind farms can increase night time temperatures, research reveals, The Guardian, April 29, 2012, http://www.guardian.co.uk/environment/2012/apr/29/windfarms-night-temperatures-study.

[8] Dawkins, R., The Selfish Gene (30th Anniversary edition), Oxford University Press, 2006.

[9] Diac M., Proiectele eoliene sunt tot mai controversate din punctul de vedere al protectiei mediului, Green Report, November 25, 2011, http://www.green-report.ro/stiri/proiectele-eolienesunt-tot-mai-controversate-din-punctul-de-vedere-al-protectiei-mediului(in Romanian).

[10] Dzitac I., Bărbat B.E., Artificial Intelligence + Distributed Systems =Agents, INT J COMPUT COMMUN, ISSN 1841-9836, 4(1):17-26, 2009. 
[11] Eilperin J., Mufson S., Renewable Energy's Environmental Paradox, Washington Post, April 16, 2009.

[12] Esbjorn-Hargens S., Integral Ecology, A post-metaphysical approach to environmental phenomena, AQAL - Journal of Integral Theory and Practice, Spring 2006, 1(1):305-378: http://jfk-integral-life.up.seesaa.net/image/Vol1_No1_Final_02_11_07_opt.pdf.

[13] European Council, Conclusions 1/2 March 2012, Brusells, http://www.consilium.europa.eu/ uedocs/cms_Data/docs/pressdata/en/ec/128520.pdf.

[14] European Union, Digital Agenda: Commission opens public consultation on how to reduce the cost of rolling out high speed internet, Press Release 27.04.2012: http://europa.eu/rapid/ pressReleasesAction.. o reference $=\mathrm{IP} / 12 / 434 \&$ format $=$ HTML\&language $=\mathrm{EN}$.

[15] European Wind Energy Association - report, Green growth - the impact of wind energy on jobs and the economy: http://www.ewea.org/fileadmin/ewea_documents/documents/publications/ reports/Green_Growth.pdf, (retrieved April, 2012).

[16] Fabian R. D., Bounded Rationality in Agent Orientation - "Just-inTime"Visual Pattern Recognition, $\mathrm{PhD}$ Thesis in Computer Science and Information Technology, Sibiu, 2011, Copyright: LBUS, Ralf D. Fabian, http://bcu.ulbsibiu.ro/digitale/doctorate/Ralf_Fabian_Phd_Thesis.pdf.

[17] Fabian R.D., M.J. Manolescu, L. Galea, G. Bologa, Bounded Rationality through the Filter of the Lisbon Objectives, INT J COMPUT COMMUN, ISSN 1841-9836, 5(5):710-718, 2010.

[18] Global Wind Energy Council, Global Wind Report, Annual Market update 2011, http://www.gwec.net/fileadmin/documents/NewsDocuments/Annual_report_2011_lowres.pdf.

[19] Oprean C., Brumar C. I., Canter M., Bărbat B. E., Sustainable Development: E-teaching (now) for Lifelong e-Learning, Procedia - Social and Behavioral Sciences, ISSN: 1877-0428, ELSEVIER, pp. 988-992, 2011, http://www.sciencedirect.com/science/article/pii/S1877042811020179

[20] Oprean C., Fabian R. D., Brumar C. I., Bărbat B. E., Bounded Rationality for "Just in Time" Education, Procedia - Social and Behavioral Sciences, ISSN: 1877-0428, ELSEVIER,pp. 983-987, 2011 : http://www.sciencedirect.com/science/article/pii/S1877042811020167.

[21] Pearce-Higgins J. W. et al., Greater impacts of wind farms on bird populations during construction than subsequent operation: results of a multi-site and multi-species analysis, Journal of Applied Ecology, 49(2):386-394, April, 2012.

[22] Seel N. M., Encyclopedia of the Sciences of Learning, Springer, 2011.

[23] Ulhoi J. P., Henning M., Sustainable Development and Sustainable Growth: Conceptual Plain or Points on a Conceptual Plain? http://www.systemdynamics.org/conferences/1999/PAPERS/PARA197.PDF. 